\title{
REMOÇÃO DE N E P DE EFLUENTE DOMÉSTICO POR PLANTAS AQUÁTICAS FLUTUANTES
}

Marcela do Carmo Vieira, Carlos Henrique dos Santos, Camila Dias Pinaffi, Maria Helena de Morais, Aline da Silva Leonardo

Universidade do Oeste Paulista - UNOESTE, Programa de Pós-Graduação em Agronomia, Presidente Prudente, SP. Email: mvieira@unoeste.br

\section{RESUMO}

O objetivo do trabalho foi avaliar a ação de três espécies de plantas aquáticas denominadas de Eichhornia crassipes, Pistia stratiotes e Salvinia auriculata na remoção das frações de N e P disponíveis do efluente de um sistema de tratamento de esgoto doméstico, do distrito de Montalvão, em Presidente Prudente/SP. Os tratamentos foram caracterizados em: $(\mathrm{T} 1)=$ efluente sem a presença de plantas; $(\mathrm{T} 2)$ = efluente com Eichhornia crassipes; (T3) = efluente com Pistia stratiotes; (T4) = efluente com Salvinia auriculata, seguindo o delineamento estatístico inteiramente casualizado, com quatro tratamentos, em parcelas subdivididas, com cinco repetições. Analisaram-se a concentração de $\mathrm{NH}_{4}{ }^{+}, \mathrm{NO}_{3}{ }^{-}$e $\mathrm{P}$ disponíveis do efluente e seus teores no tecido vegetal (raízes, bulbos e folhas). Houve remoção de $\mathrm{NH}_{4}{ }^{+}$e de $\mathrm{P}$ pelas plantas aquáticas em relação ao tratamento testemunha; as taxas de remoção do $\mathrm{NH}_{4}{ }^{+}$do efluente foram diferenciadas entre as espécies e entre os ciclos de avaliação mensal; a Eichhornia crassipes apresentou maior eficiência na remoção do $\mathrm{P}$ do efluente no decorrer de todos os ciclos de avaliação mensal; a Salvinia auriculata apresentou maior teor de $\mathrm{NH}_{4}{ }^{+}$e $\mathrm{P}$ no tecido (raízes, bulbos e folhas).

Palavras-chave: macrófitas; fitorremediação; nutrientes.

\section{REMOVAL OF N AND P IN WASTEWATER BY FLOATING PLANTS}

\begin{abstract}
The objective of this work was to evaluate the action of three species of aquatic plants called Eichhornia crassipes, Pistia stratiotes and Salvinia auriculata in the removal of available $\mathrm{N}$ and $\mathrm{P}$ fractions from the effluent of a domestic sewage treatment system in the district of Montalvão, in Presidente Prudente/SP. The treatments were characterized in: $(T 1)=$ effluent without the presence of plants; $(T 2)=$ effluent with Eichhornia crassipes; (T3) = effluent with Pistia stratiotes; (T4) = effluent with Salvinia auriculata, following the completely randomized design, with four treatments, in subdivided plots, with five replications. The available $\mathrm{NH}_{4}{ }^{+}, \mathrm{NO}_{3}{ }^{-}$and $\mathrm{P}$ concentrations of the effluent and their contents in the plant tissue (roots, bulbs and leaves) were analyzed. There was removal of $\mathrm{NH}_{4}{ }^{+}$and $\mathrm{P}$ by aquatic plants in relation to the control treatment; the $\mathrm{NH}_{4}{ }^{+}$removal rates of the effluent were differentiated between the species and between the monthly evaluation cycles; the Eichhornia crassipes presented greater efficiency in the removal of $P$ from the effluent during all the monthly evaluation cycles; Salvinia auriculata presented higher levels of $\mathrm{NH}_{4}{ }^{+}$and $\mathrm{P}$ in the tissue (roots, bulbs and leaves).
\end{abstract}

Keywords: macrophytes; phytoremediation; nutrients.

\section{INTRODUÇÃO}

O tratamento de esgotos domésticos apresenta enorme relevância para o saneamento de um município, pois assegura o bem-estar e a saúde pública (SOARES et al., 2016). No entanto, a falta de tratamento dos esgotos domésticos é considerada um dos maiores problemas ambientais da população brasileira (LEMES et al., 2009), sendo um dos meios contribuintes para impactos negativos à população e ao ecossistema aquático, ocasionando danos que muitas vezes podem ser irreversíveis (SOARES et al., 2016).

Com o intuito de reduzir os efeitos negativos causados ao meio ambiente proveniente de efluentes, os domésticos em particular, pesquisadores têm se dedicado ao estudo de processos de recuperação de efluentes através de métodos alternativos que sejam 
econômicos e tecnologicamente adequados para o tratamento do esgoto, a fim de contribuir com a qualidade ambiental. As macrófitas aquáticas destacam-se nesta modalidade de tratamento devido a sua alta eficiência na retenção e bioabsorção (VIRENDRA; TRIPATHI, 2008).

Os sistemas de alagados construídos com a presença de plantas aquáticas possuem resultados comprovados de eficiência na remoção de nutrientes, como nitrogênio (N) e fósforo (P). Para Sezerino e Philippi (2000), nesses sistemas de tratamento, aproximadamente $74 \%$ da remoção do $\mathrm{N}$ amoniacal pode ser associada a uma assimilação por parte das plantas. Sousa et al. (2004) salientam que para a remoção específica de $P$, o tipo de vegetação e a composição química do material suporte podem ter interferência significativa, já que os principais mecanismos de remoção do atributo no sistema são a bioadsorção pelos substratos e a assimilação química pelos vegetais.

Esta pesquisa objetivou avaliar a ação de três espécies de plantas aquáticas denominadas de Eichhornia crassipes, Pistia stratiotes e Salvinia auriculata na remoção das frações de $\mathrm{N}$ e $\mathrm{P}$ disponíveis do efluente de um sistema de tratamento de esgoto doméstico.

\section{MATERIAL E MÉTODOS}

Tabela 1. Atributos químicos* do efluente bruto da ETE utilizado nos tratamentos

\begin{tabular}{cc}
\hline Parâmetros & Valores \\
\hline $\mathrm{DQO}\left(\mathrm{mg} \mathrm{L}^{-1}\right)$ & 176,00 \\
$\mathrm{DBO}_{5} 2 \mathrm{C}^{\circ} \mathrm{C}\left(\mathrm{mg} \mathrm{L}^{-1}\right)$ & 50,00 \\
$\mathrm{Cor}(\mathrm{hz})$ & 190,00 \\
Turbidez (FTU) & 186,00 \\
$\mathrm{pH}$ & 8,30 \\
Condutividade elétrica $\left(\mu \mathrm{Scm}^{-1}\right)$ & 530,00 \\
$\mathrm{NH}_{4}^{+}\left(\mathrm{mg} \mathrm{L}^{-1}\right)$ & 22,32 \\
$\mathrm{NO}_{3}^{-}\left(\mathrm{mg} \mathrm{L}^{-1}\right)$ & 1,13 \\
$\mathrm{NO}_{2}^{-}\left(\mathrm{mg} \mathrm{L}^{-1}\right)$ & 0,76 \\
$\mathrm{P}\left(\mathrm{mg} \mathrm{L}^{-1}\right)$ & 0,60 \\
$\mathrm{~K}\left(\mathrm{mg} \mathrm{L}^{-1}\right)$ & 13,10 \\
$\mathrm{Ca}\left(\mathrm{mg} \mathrm{L}^{-1}\right)$ & 3,10 \\
$\mathrm{Mg}\left(\mathrm{mg} \mathrm{L}^{-1}\right)$ & 2,50 \\
$\mathrm{~S}\left(\mathrm{mg} \mathrm{L}^{-1}\right)$ & 0,70 \\
$\mathrm{Na}\left(\mathrm{mg} \mathrm{L}^{-1}\right)$ & 87,20 \\
$\mathrm{Cu}\left(\mathrm{mg} \mathrm{L}^{-1}\right)$ & 0,20 \\
$\mathrm{Fe}\left(\mathrm{mg} \mathrm{L}^{-1}\right)$ & 0,80 \\
$\mathrm{Mn}\left(\mathrm{mg} \mathrm{L}^{-1}\right)$ & 0,10 \\
$\mathrm{Zn}\left(\mathrm{mg} \mathrm{L}^{-1}\right)$ & 0,10 \\
$\mathrm{Cr}\left(\mathrm{mg} \mathrm{L}^{-1}\right)$ & 4,41 \\
$\mathrm{~Pb}\left(\mathrm{mg} \mathrm{L}^{-1}\right)$ & 1,70
\end{tabular}

* Valores obtidos neste período de análises.
O experimento foi conduzido em área da estação de tratamento de esgoto (ETE) localizado no distrito de Montalvão, na região de Presidente Prudente/SP. A área está localizada a $430 \mathrm{~m}$ de altitude em uma região de clima definido como Cwa, conforme classificação de Köppen. As coordenadas geográficas da ETE de Montalvão são: Latitude: $22^{\circ} 04^{\prime} 84^{\prime \prime} \mathrm{S}$ e Longitude: $51^{\circ} 35^{\prime} 91^{\prime \prime} W$.

$\mathrm{Na}$ instalação do experimento, $250 \mathrm{~L}$ de efluente foram bombeados da lagoa facultativa para 20 recipientes de PVC com capacidade para 320 L os quais receberam plantas de aguapé (Eichhornia crassipes), alface d'água (Pistia stratiotes) e Salvínia (Salvinia auriculata). As espécies vegetais foram coletadas no manancial do rio Santo Anastácio, no município de Presidente Prudente/SP, sendo caracterizadas como plantas jovens, de tamanho uniforme, com sistema radicular estabelecido e parte aérea de aparência uniforme. As mesmas permaneceram nos recipientes com água durante 15 dias para aclimatação ambiental e depois foram introduzidas no efluente.

Anteriormente à instalação do experimento, realizou-se a caracterização química do efluente bruto da ETE. Os valores dos parâmetros estão apresentados na Tabela 1. 
Os tratamentos foram caracterizados como: $(T 1)$ = efluente sem a presença de plantas; (T2) = efluente com Eichhornia crassipes; (T3) = efluente com Pistia stratiotes; $(\mathrm{T} 4)=$ efluente com Salvinia auriculata, seguindo o delineamento estatístico inteiramente casualizado com quatro tratamentos, em parcelas subdivididas, com cinco repetições, onde as parcelas foram consideradas a presença de plantas aquáticas no efluente e as subparcelas os períodos de coleta de dados das análises químicas do efluente e do tecido vegetal (raízes, bulbos e folhas). Posteriormente, exemplares das plantas foram transferidos para os recipientes mantendo-se a taxa de ocupação de $80 \%$ da área dos mesmos.

As coletas mensais de efluente foram realizadas em três ciclos subsequentes de manejo, totalizando três meses de experimentação (Abril, Maio e Junho/2013). Ao final de cada ciclo ocorreu a coleta e a substituição das plantas em cada tratamento, sem, contudo, realizar a substituição do efluente. Foram coletadas cinco amostras simples de cada recipiente, as quais foram misturadas para formar uma amostra composta de cada parcela.

Determinaram-se a concentração do $\mathrm{N}$ nas formas de $\mathrm{NH}_{4}{ }^{+}$e de $\mathrm{NO}_{3}{ }^{-}\left(\mathrm{mg} \mathrm{L}^{-1}\right)$ além do $\mathrm{P}$ ( $\mathrm{mg} \mathrm{L}^{-1}$ ) disponíveis. Para isso, as amostras foram filtradas em papel de filtro faixa azul, de filtração lenta, obtendo-se uma alíquota de $100 \mathrm{~mL}$. Em seguida os extratos foram encaminhados para a extração das frações de $\mathrm{N}$ pelo método de destilação à vapor (Kjeldahl) e posterior determinação por titulometria, e para a quantificação do $\mathrm{P}$ por espectrofotometria em UV-Vis, realizada no espectrofotômetro a 420 $\mathrm{nm}$, modelo Lambda XLS+, PerkiElmer. Os procedimentos de extração e determinação elementar foram realizados de acordo com as metodologias descritas por Malavolta et al. (1997).

Durante o mês de maio de 2013, foi evidenciada a necessidade de complementação do volume de efluente, em cada tratamento, até o nível determinado no início do experimento (250 L), a cada cinco dias, em função do índice de evapotranspiração local. A reposição foi realizada com o próprio efluente da lagoa de tratamento.

As coletas de amostras de tecido vegetal (planta inteira) destinadas à análise química foram realizadas a cada 28 dias e analisadas estatisticamente de maneira independente. No total, foi coletada uma amostra/parcela para a extração e a determinação dos teores de $\mathrm{NH}_{4}{ }^{+}$, $\mathrm{NO}_{3}{ }^{-}$e $\mathrm{P}$ de acordo com as metodologias descritas por Malavolta et al. (1997). Na quantificação do $\mathrm{NH}_{4}^{+}, \mathrm{NO}_{3}{ }^{-}$e $\mathrm{P}$ nas plantas foram utilizados os mesmos equipamentos citados para a determinação dos elementos no efluente.

Os resultados obtidos foram submetidos à análise de variância e ao teste de Tukey para a comparação de médias, ao nível de $5 \%$ de probabilidade. Para avaliar, de forma independente, o efeito das épocas de coleta semanal dos efluentes dentro de cada ciclo foram aplicados modelos matemáticos de regressão linear e polinomial de primeira e segunda ordem. o melhor modelo para o ajuste dos dados foi escolhido em função do grau de significância do coeficiente de determinação $\left(R^{2}\right)$.

\section{RESULTADOS E DISCUSSÃO}

Foram observados reduções em todos os tratamentos das concentrações de $\mathrm{NH} 4$ nos efluentes avaliados semanalmente, de acordo com a (Figura 1 A), 1o ciclo de coleta, com maior redução a partir do 14을 dia de manejo. 
Figura 1. Concentração de $\mathrm{NH}_{4}{ }^{+}$disponível no $1^{\circ}$ ciclo (A), no $2^{\circ}$ ciclo (B) e no $3^{\circ}$ ciclo (C) de avaliação, nos tratamentos com efluentes da ETE em quatro períodos de coleta. Ajustes significativos $\left(p<0,05^{*}\right)$, $\left(0,01<p<0,05^{* *}\right)$, ns - não significativo.

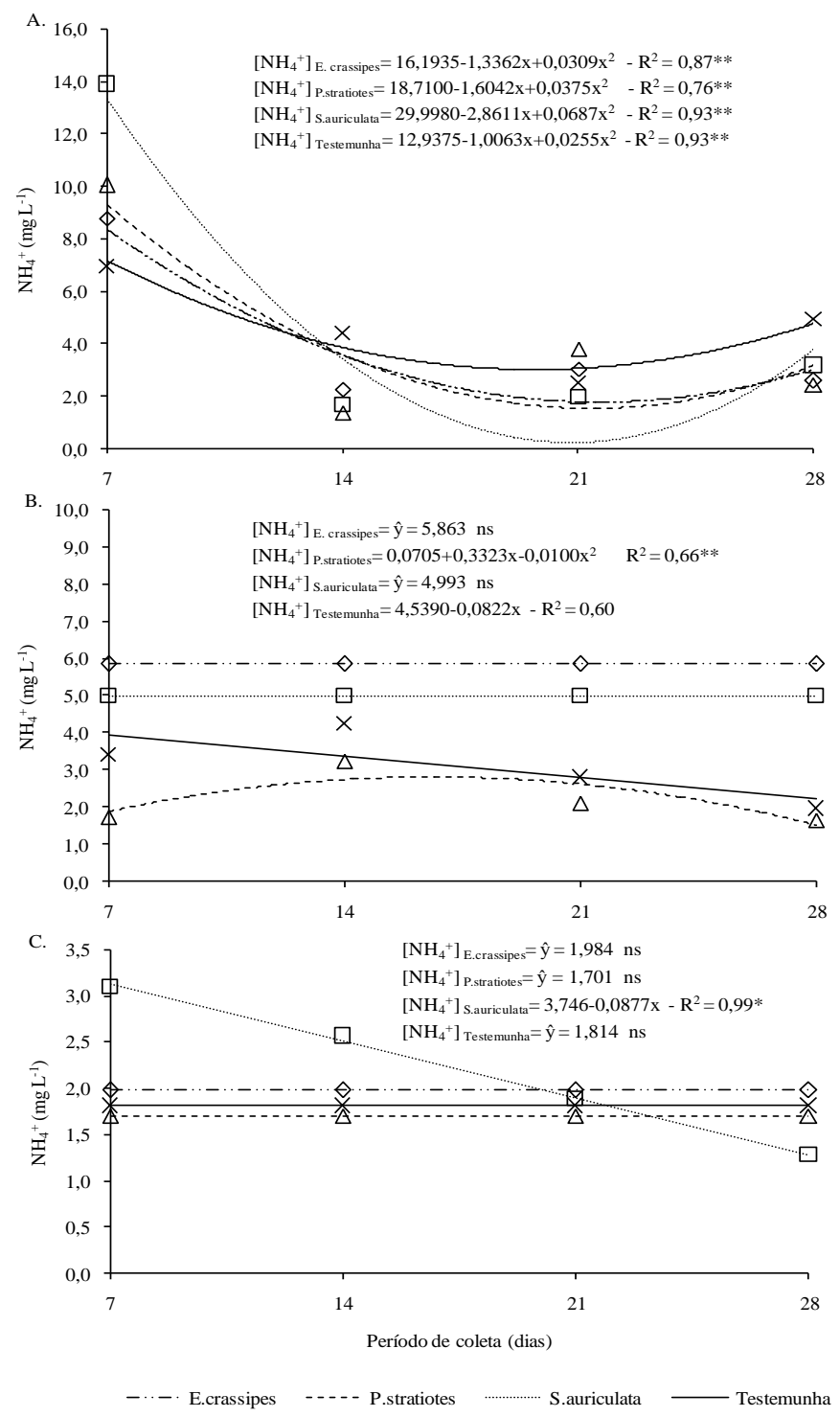

A espécie Salvinia auriculata apresentou $36,8 \%$ de eficiência de remoção de $\mathrm{NH}_{4}{ }^{+}$, seguida da Eichhornia crassipes e Pistia stratiotes, com 28,7 e $28,3 \%$ de eficiência, respectivamente, em relação ao tratamento não vegetado. As plantas reduziram a concentração de $\mathrm{NH}_{4}{ }^{+}$no $1^{\circ}$ ciclo de avaliação, embora seja importante ressaltar que houve efeito de diluição do efluente em virtude da ocorrência de chuva no período, favorecendo na diminuição da concentração do elemento no efluente.

Nos $2^{\circ}$ e $3^{\circ}$ ciclos de avaliação (Figuras $1 \mathrm{~B}$ e $1 C$ ), mesmo com a substituição de todas as plantas, a Pistia stratiotes foi responsável pela redução de 28,6 e $6,2 \%$ na concentração de $\mathrm{NH}_{4}{ }^{+}$ no efluente, respectivamente. A substituição das plantas foi realizada para manter a remoção satisfatória do composto químico do efluente. A biomassa das plantas cultivadas em sistemas alagados construídos deve ser regularmente removida e substituída para assegurar elevada remoção de nutrientes do meio, pois o objetivo principal é a redução da carga poluente (EUSTÁQUIO JR. et al., 2010).

O polimento no tratamento do efluente de esgoto doméstico pode contemplar não apenas espécies dos gêneros Pistia, Salvinia e Eichhornia. Ucker et al. (2012) observaram eficiência de $83,8 \%$ na remoção do $\mathrm{NH}_{4}{ }^{+}$total para os sistemas de tratamento de esgoto sanitário utilizando capim vetiver (Vetiveria zizanioides), enquanto no manejo sem plantas aquáticas a remoção de $\mathrm{NH}_{4}{ }^{+}$foi em média de $42,5 \%$. A concentração de $N$ no efluente na presença do capim foi de $3,8 \mathrm{mg} \mathrm{L}^{-1}$, enquanto que no manejo sem plantas igual a $9,3 \mathrm{mg} \mathrm{L}^{-1}$. Considerando que, os efluentes de esgoto sanitário apresentam, em média, concentração 
de $50 \mathrm{mg} \mathrm{L}^{-1}$ de $\mathrm{N}$ e $8,1 \mathrm{mg} \mathrm{L}^{-1}$ de $\mathrm{P}$ (VON SPERLING, 2005) o sinergismo entre o tratamento convencional e o polimento final por plantas aquáticas proporciona resultados com eficiência significativa ao sistema.

Nos dois últimos ciclos de avaliação (Figuras 1B e 1C), o tratamento sem plantas apresentou diminuição significativa da concentração de $\mathrm{NH}_{4}{ }^{+}$, cujos valores estiveram próximos àqueles observados nos tratamentos vegetados. A proximidade entre os valores esteve relacionada à baixa concentração de $\mathrm{NH}_{4}{ }^{+}$no efluente na presença das espécies vegetais. Com a sua rápida absorção no decorrer do tempo, houve redução na disponibilidade de $\mathrm{N}$ no meio, ocasionando redução da atividade metabólica e de sua absorção pelas plantas. Nos $2^{\circ}$ e $3^{\circ}$ ciclos, a diminuição da disponibilidade de $\mathrm{N}$ no efluente proporcionou a estabilidade na concentração do elemento até o 28ㅇ dia de manejo na maioria dos tratamentos.

Além do $\mathrm{NH}_{4}^{+}$, formas de $\mathrm{N}$ inorgânico como $\mathrm{O} \mathrm{NO}_{3}^{-}$têm importância no estudo de sistemas alagados com macrófitas (MENDONÇA et al., 2012). A concentração de $\mathrm{NO}_{3}{ }^{-}$do efluente doméstico foi monitorada em todos os ciclos experimentais (Figuras 2A e 2B).

Figura 2. Concentração de $\mathrm{NO}_{3}{ }^{-}$disponível no $2^{\circ}$ ciclo (A) e no $3^{\circ}$ ciclo (B) de avaliação, nos tratamentos com efluentes da ETE, em quatro períodos de coleta. Ajustes significativos $(p<0,05 *),\left(0,01<p<0,05^{* *}\right)$, ns - não significativo.

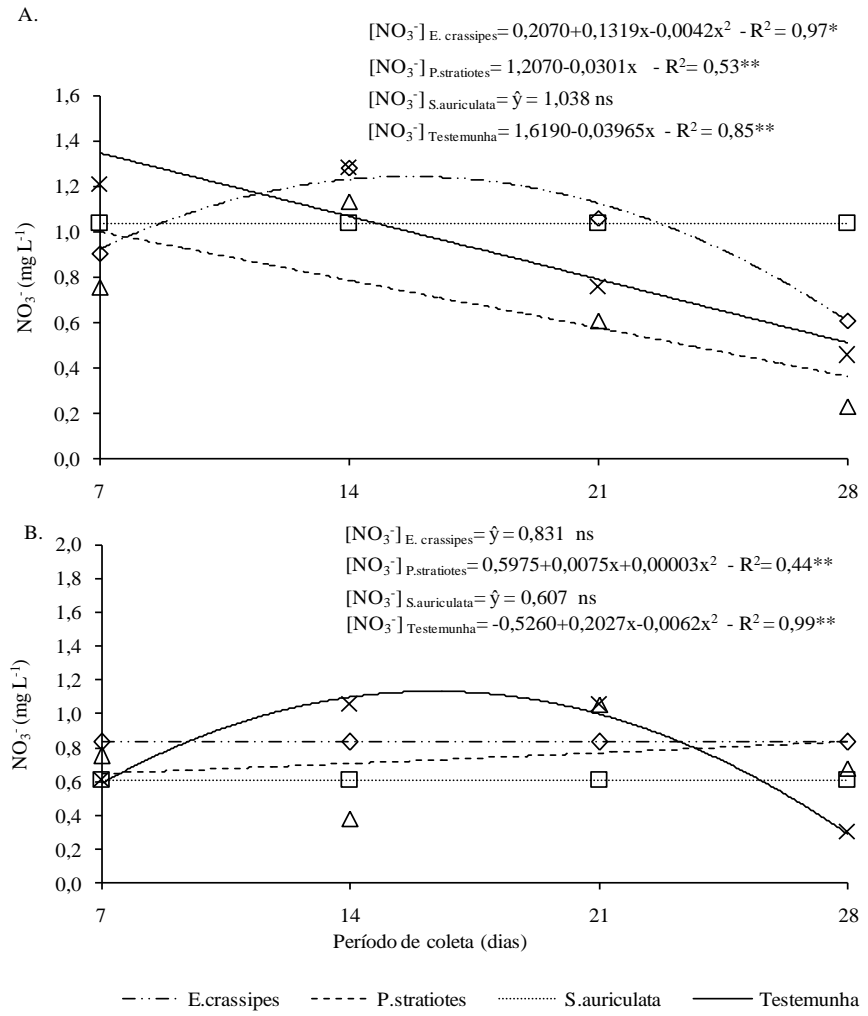

Os valores do $1^{\circ}$ ciclo de avaliação ficaram abaixo do limite de detecção do método analítico e não pôde ser apresentada. Nos $2^{\circ}$ e $3^{\circ}$ ciclos, a concentração de $\mathrm{NO}_{3}{ }^{-}$foi menor que do $\mathrm{NH}_{4}{ }^{+}$em todos os tratamentos e, se manteve constante até o 28 o dia de coleta semanal, no último ciclo mensal (Figura 2B). A dispinibilidade de $\mathrm{NO}_{3}{ }^{-}$diminuiu no decorrer das coletas semanais, no $2^{\circ}$ ciclo mensal (Figura 2A) em todos os tratamentos.

Em ambientes aquáticos manejados com plantas, o fator bioadsorção pelas raízes deve-se ser considerado. Porém, no ambiente sem plantas (Figuras 2 A e 2B), a redução da concentração de $\mathrm{NO}_{3}{ }^{-}$pode ter ocorrido diante da reduzida disponibilidade de oxigênio no ambiente, conforme verifica-se nos valores de DBO (Demanda Bioquímica de Oxigênio) e DQO (Demanda Química de Oxigênio) da caracterização do efluente (Tabela 1). Assim, pode ter surgido condição para a desnitrificação do $\mathrm{NO}_{3}^{-}$a $\mathrm{N}$ elementar e a perda deste para a atmosfera. Nos processos biológicos, em condições predominantemente anóxicas ocorre à oxidação do íon $\mathrm{NH}_{4}^{+}$a $\mathrm{N}$ com posterior 
volatilização do elemento (VAN DE GRAAF et al., 1996).

Entretanto, os sistemas alagados vegetados também apresentam considerável capacidade de nitrificação e desnitrificação do $\mathrm{N}$ devido à presença de sítios aeróbios proporcionados pela transferência de oxigênio da planta para o meio aquoso anóxico, através das raízes (SEZERINO, 2006). Neste caso, a redução do $\mathrm{NH}_{4}{ }^{+}$pode ser explicada por esta transferência do oxigênio para o efluente, sendo este utilizado pelas bactérias nitrificantes para oxidar o $\mathrm{NH}_{4}{ }^{+}$a $\mathrm{NO}_{3}^{-}$(MENDONÇA, 2010). Portanto, pode-se considerar que a saída de $\mathrm{NO}_{3}^{-}$de um sistema aquático vegetado pode ser quantificado através da análise química do tecido vegetal, mas uma parte não é quantificada em função da perda do $\mathrm{N}$ pela nitrificação e posterior desnitrificação e volatilização para a atmosfera.

Considera-se ainda que as concentrações de $\mathrm{NH}_{4}^{+}$e $\mathrm{NO}_{3}^{-}$no efluente (Figuras $2 \mathrm{~A}$ e $2 \mathrm{~B}$ ) indicaram que houve baixa taxa de nitrificação nos ambientes, pois os valores de $\mathrm{NO}_{3}^{-}$dos tratamentos com plantas aquáticas foram próximos dos encontrados no efluente sem vegetação. Nos tratamentos vegetados, o tempo de permanência do $\mathrm{NH}_{4}^{+}$na solução não favoreceu a nitrificação e, no caso, do tratamento sem plantas, a oxigenação do efluente também não proporcionou condições para uma elevada taxa de oxidação do $\mathrm{NH}_{4}^{+}$.

Ferres et al. (2013), ao estudar a remoção de $\mathrm{N}$ total, $\mathrm{NO}_{3}^{-}$e $\mathrm{NH}_{4}^{+}$em sistemas alagados com as espécies Cynodon spp. e Alternanthera philoxeroides, constataram aumento da concentração de $\mathrm{NO}_{3}{ }^{-}$e simultânea redução de
$\mathrm{NH}_{4}{ }^{+}$, sugerindo a ocorrência de amonificação do $\mathrm{NO}_{3}^{-}$no sistema. Assim como, a possível preferência da macrófita em absorver $\mathrm{NH}_{4}{ }^{+}$como nutriente ao invés de $\mathrm{NO}_{3}{ }_{3}^{-}$por possuir uma forma mais reduzida energeticamente.

De acordo com os resultados das Figuras $1 \mathrm{~A}, 1 \mathrm{~B}$ e $1 \mathrm{C}$, neste estudo, corraboram com os resultados avaliados por Shah et al. (2015), cujas concentrações de $\mathrm{N}$ amoniacal para as espécies Eichhornia crassipes, Lemna minor e Pistia stratiotes reduziram de 2,42 a $1,45 \mathrm{mg} \mathrm{L}^{-1}$ (40,34\%), 2,37 a $1,95 \mathrm{mg} \mathrm{L}^{-1}(17,59 \%)$ e 2,42 para $2,09 \mathrm{mg} \mathrm{L}^{-1}(14,45 \%)$, respectivamente.

Segundo Esteves (1998), as macrófitas Eichhornia crassipes, Pistia stratiotes e Thypha sp. absorveram mais $\mathrm{NH}_{4}{ }^{+}$porque esta forma de $\mathrm{N}$ é energeticamente mais viável para o metabolismo, não havendo a necessidade de sua transformação no tecido para ser incorporado às estruturas carbônicas constituintes da biomassa, como observado na bioadsorção de $\mathrm{NO}_{3}^{-}$, que precisa ser reduzido à $\mathrm{NH}_{4}^{+}$pela ação enzimática redutase do nitrato.

Shutes (2001) e Mendonça et al. (2012) salientaram que o uso de sistemas alagados para tratamentos de águas residuária provenientes de efluentes domésticos, além de proporcionar eficiência na remoção de matéria orgânica biodegradável dos efluentes apresentando considerável capacidade de remoção de nutrientes como o $\mathrm{P}$.

As Figuras $3 \mathrm{~A}$ e $3 \mathrm{~B}$ mostram aumento na concentração de $\mathrm{P}$ no efluente nos dois primeiros ciclos para todos os tratamentos, até o 28ㅇdia de coleta de amostras. 
Figura 3. Concentração de $P$ disponível no $1^{\circ}$ ciclo (A), no $2^{\circ}$ ciclo (B) e no $3^{\circ}$ ciclo (C) de avaliação nos tratamentos com efluentes da ETE, em quatro períodos de coleta. Ajustes significativos $\left(0,01<p<0,05^{* *}\right)$, ns - não significativo.

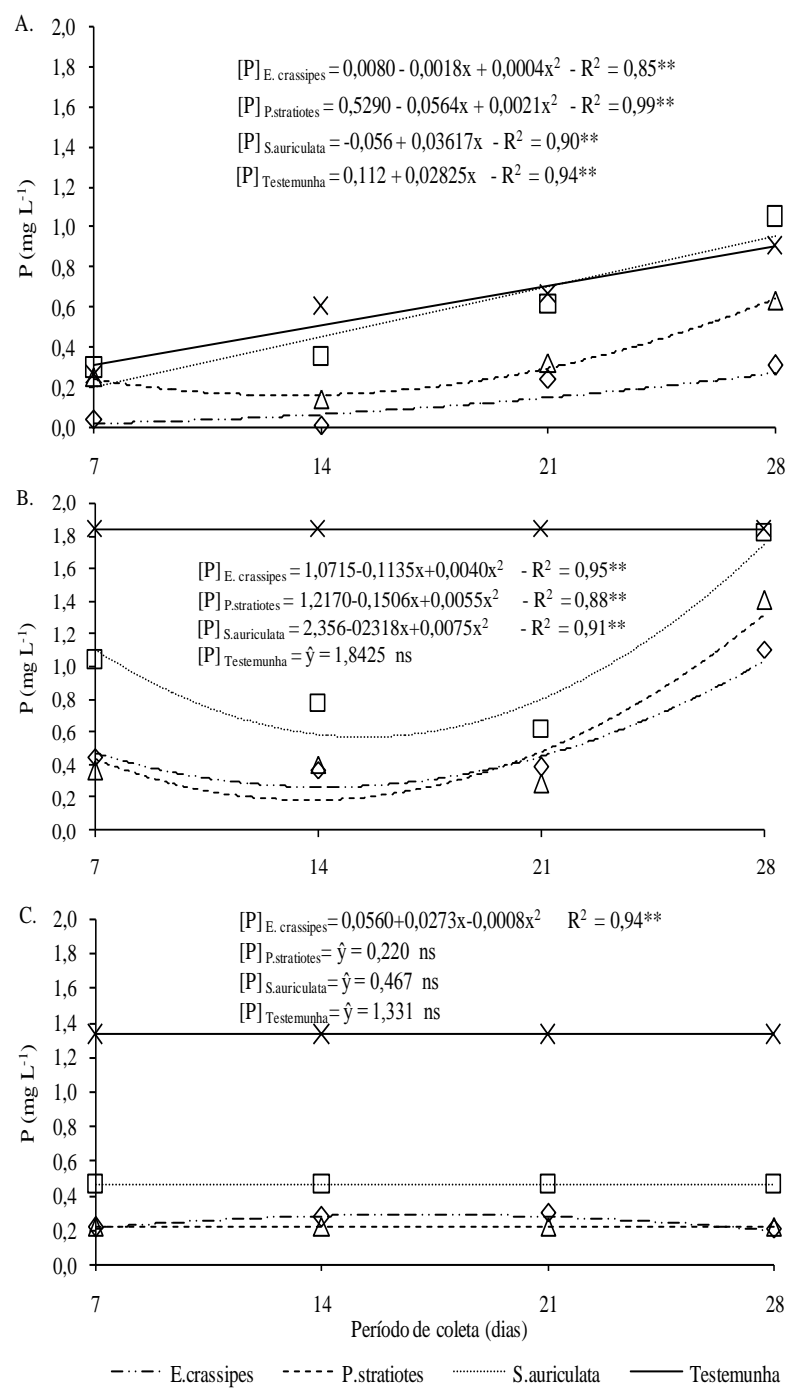

As concentrações de $P$ no efluente manjeado com as macrófitas foram menores quando comparadas à testemunha não vegetada, evidenciando a potencialidade das espécies estudadas na assimilação deste nutriente (Figuras 3A e 3B). Gopal (1990) observou que a Salvinia auriculata, em condições naturais, apresentou concentração de $\mathrm{N}$ e $\mathrm{P}$ superiores à outras espécies.

$\mathrm{O}$ deslocamento do $\mathrm{P}$ nas águas é parte fundamental do seu ciclo e, o comportamento deste elemento em rios e reservatórios relacionase diretamente com o nível e a intensidade das contribuições, sejam elas naturais, que ocorre principalmente por meio das erosões do solo, num processo lento em que parte do fosfato é transportada para a hidrosfera, meio onde pode sedimentar-se ou ser utilizado pelos seres vivos, ou artificiais, que são aquelas decorrentes da atividade humana, destacam-se os esgotos domésticos, os efluentes industriais e o escoamento superficial de áreas cultivadas (VON SPERLING, 2005). A redução da concentração de $\mathrm{P}$ se deve principalmente à sua assimilação pelas plantas, sendo parte convertida em material celular e outra precipitada sob diferentes formas químicas no metabolismo intracelular da planta (DINIZ et al., 2005). Almeida et al. (2007) relataram que, em sistema do tipo zona de raízes, o tratamento com a taboa (Typha angustifolia L.) reduziu os teores de fosfatos nos efluentes em $72 \%$. Porém, de acordo com Diniz et al. (2005), a retirada periódica do excesso de macrófitas do ambiente é de suma importância para manter o efeito de biofiltro, a eficiência de redução de componentes poluentes bem como evitar que a decomposição do tecido vegetal, diante da senescência das plantas, possa contribuir com o aumento das formas elementares de $\mathrm{N}$ e $\mathrm{P}$ ao ambiente aquático.

Ao contrário do que ocorreu no $1^{\circ}$ ciclo com $\mathrm{O} \mathrm{NH}_{4}{ }^{+}, \quad \mathrm{P}$ teve sua concentração 
aumentada no efluente. No início do período de avaliação (Figura $3 \mathrm{~A}$ ) a concentração de $\mathrm{P}$ pode ter sido diluída em função da precipitação pluviométrica ocorrida neste período. Posteriormente, a precipitação cessou e, com a evapotranspiração local intensificada houve efeito de concentração de $\mathrm{P}$ no efluente (Figura $3 A)$. Pela maior concentração de $\mathrm{NH}_{4}{ }^{+}$disponível em solução em relação ao $P$, esta diluição foi menos acentuada para o $\mathrm{N}$.

Ucker et al. (2012) verificaram redução de $80,4 \%$ no teor de $\mathrm{P}$ total do efluente na presença do capim vetiver comparado aos ambientes de manejo sem planta, onde a redução média foi de $44,6 \%$. Os valores de $P$ apresentados nas Figuras $3 A, 3 B$ e $3 C$ são menores que os citados por Ucker et al. (2012) e Von Sperling (2005) pois trata-se do teor de $\mathrm{P}$ disponível no efluente.

No $3^{\circ}$ ciclo de avaliação (Figura $3 \mathrm{C}$ ), já com outro lote de plantas inseridas nos tratamentos, a concentração de $\mathrm{P}$ no efluente permaneceu constante no decorrer dos períodos de coletas semanais. As espécies Eichhornia crassipes, Salvinia auriculata e Pistia stratiotes reduziram a concentração de $\mathrm{P}$ comparado ao tratamento sem plantas.

Em cada início do período mensal de avaliação (Figuras 3A, 3B e 3C) a concentração de $P$ disponível na presença das macrófitas sempre iniciaram com os menores valores comparados ao ambiente não vegetado, indicando uma eficiência de remoção de 77,1, 65,1 e 37,5\%, respectivamente, para a Eichhornia crassipes,
Pistia stratiotes e Salvinia auriculata. Henry-Silva e Camargo (2008) encontraram remoção de $P$ total entorno de $71,6 \%$ nos tratamentos com Eichhornia crassipes e $69,9 \%$ com Pistia stratiotes.

O principal mecanismo de remoção de $\mathrm{P}$ consiste na bioadsorção e incorporação do mesmo na biomassa das macrófitas, embora existam outros mecanismos como o de retenção do $P$ envolvendo fenômenos de precipitação, sedimentação e, principalmente, bioadsorção do $P$ na superfície das raízes das plantas aquáticas (ARIAS et al., 2001).

Para Barbieri e Esteves (1991), o conhecimento da composição química das macrófitas é importante pois informa sobre a capacidade de armazenamento de nutrientes no tecido vegetal, sobre a disponibilidade dos mesmos para o crescimento (GERLOFF; KROMBHOLZ, 1966) e sobre o valor nutricional das plantas (HENRY-SILVA; CAMARGO, 2006). Entretanto, para investigar o papel desta vegetação em ecossistemas aquáticos, é necessário considerar a composição química destas em relação às condições locais, pois a vegetação é parcialmente afetada por mudanças sazonais no ambiente (COSTA; HENRY, 2010).

Os resultados apresentados na Tabela 2 mostram diferença estatística significativa no teor de $\mathrm{NH}_{4}{ }^{+}$no tecido entre Salvinia auriculata e as espécies Eichhornia crassipes e Pistia stratiotes, destacando que as últimas não apresentaram diferença entre si (Tabela 2).

Tabela 2. Teores de $\mathrm{NH}_{4}^{+}$e $\mathrm{NO}_{3}^{-}$das espécies Eichhornia crassipes, Pistia stratiotes e Salvinia auriculata nos tratamentos com efluente da ETE

\begin{tabular}{lcc}
\hline \multicolumn{1}{c}{ Espécies } & $\mathrm{NH}_{4}^{+}$ & $\mathrm{NO}_{3}^{-}$ \\
\hline Eicchornia crassipes & $10,87 \mathrm{~b}$ & $2,23 \mathrm{a}$ \\
Pistia stratiotes & $18,53 \mathrm{~b}$ & $2,42 \mathrm{a}$ \\
Salvinia auriculata & $35,00 \mathrm{a}$ & $1,79 \mathrm{a}$ \\
\hline dms & 12,87 & 3,16 \\
\hline
\end{tabular}

As médias seguidas pela mesma letra não diferem estatisticamente entre si. Foi aplicado o Teste de Tukey ao nível de 0,05 de probabilidade.

Estes resultados estão em concordância com dados apresentados na Figura $1 \mathrm{~A}$, visto que ocorreu redução na concentração de $\mathrm{NH}_{4}^{+}$no efluente na presença da Salvinia auriculata, a partir dos 14 dias de avaliação, do $1^{\circ}$ ciclo de coleta mensal. Esta observação também é destacada na Tabela 2. Entretanto, ao mesmo tempo, não foi observada diferença estatística entre as espécies com relação à bioadsorção de $\mathrm{NO}_{3}^{-}$(Tabela 2). 
Tabela 3. Teores de $\mathrm{NH}_{4}{ }^{+}$e $\mathrm{NO}_{3}{ }^{-}$das espécies Eichhornia crassipes, Pistia stratiotes e Salvinia auriculata, nos três períodos de coleta, nos tratamentos com efluente da ETE

\begin{tabular}{lcc}
\hline Ciclos Coleta & \multicolumn{1}{c}{$\mathrm{NH}_{4}^{+}$} & $\mathrm{NO}_{3}^{-}$ \\
\hline $1^{\circ}$ ciclo (Abril) & $27,16 \mathrm{a}$ & $2,72 \mathrm{a}$ \\
$2^{\circ}$ ciclo (Maio) & $22,88 \mathrm{ab}$ & $2,85 \mathrm{a}$ \\
$3^{\circ}$ ciclo (Junho) & $14,35 \mathrm{~b}$ & $0,87 \mathrm{a}$ \\
\hline $\mathrm{dms}$ & 11,18 & 2,11
\end{tabular}

As médias seguidas pela mesma letra não diferem estatisticamente entre si. Foi aplicado o Teste de Tukey ao nível de 0,05 de probabilidade.

A concentração de $\mathrm{NH}_{4}{ }^{+}$reduziu até o $3^{\circ}$ ciclo de coleta. Mesmo realizando a coleta e a substituição das plantas em cada ciclo, o tempo deve ser considerado um fator importante para a redução da disponibilidade de $\mathrm{NH}_{4}{ }^{+}$no efluente e, consequentemente, redução no teor deste composto químico ao tecido vegetal (Tabela 3 ). Do $1^{\circ}$ ao $3^{\circ}$ ciclos houve efetiva redução no teor de $\mathrm{NH}_{4}{ }^{+}$no tecido, o que também pode ser verificado nas Figuras $1 \mathrm{~A}, 1 \mathrm{~B}$ e $1 \mathrm{C}$ para todas as espécies vegetais.

Os resultados apresentados na Tabela 4 mostram interação significativa para o $P$, nas amostras de tecido vegetal, entre as espécies vegetais e os ciclos de coletas mensais.

Tabela 4. Teores de $P$ das espécies Eichhornia crassipes, Pistia stratiotes e Salvinia auriculata, nos três períodos de coleta, nos tratamentos com efluente da ETE

Espécie Vegetal

Teor de $\mathrm{P}$

$\begin{array}{lccc} & & & \\ & 1^{\circ} \text { ciclo (Abril) } & 2^{\circ} \text { ciclo (Maio) } & 3^{\circ} \text { ciclo (Junho) } \\ \text { Eichhornia crassipes } & 3,65 \mathrm{bA} & 2,36 \mathrm{bAB} & 1,09 \mathrm{cB} \\ \text { Pistia stratiotes } & 5,36 \mathrm{aA} & 2,87 \mathrm{bB} & 3,13 \mathrm{bB} \\ \text { Salvinia auriculata } & 6,79 \mathrm{aA} & 4,95 \mathrm{aB} & 6,46 \mathrm{aA}\end{array}$

$\mathrm{dms}$ coluna = 1,58 (letras minúsculas); $\mathrm{dms}$ linha = 1,50 (letras maiúsculas)

As médias seguidas pela mesma letra não diferem estatisticamente entre si. Foi aplicado o Teste de Tukey ao nível de 0,05 de probabilidade.

A Salvinia auriculata apresentou maior teor de $\mathrm{P}$ no tecido comparado às outras duas espécies, no decorrer dos três ciclos de avaliação, diferindo significativamente da Eichhornia crassipes, a qual apresentou redução gradativa no teor de $P$ no seu tecido vegetal entre os ciclos (Tabela 4). A tendência observada para o $P$ também foi observada para o $\mathrm{NH}_{4}{ }^{+}$, embora sem o grau de significância para o fator interação. Este resultado demonstra a potencialidade da remoção deste elemento do efluente.

Petrucio e Esteves (2000) não observaram aumento na assimilação de $\mathrm{N}$ e $\mathrm{P}$ entre a Eichhornia crassipes e a Salvinia auriculata mesmo quando altas concentrações de $N$ e $P$ foram observadas na água. Para esses autores a Eichhornia crassipes bioadsorve $\mathrm{N}$ e $\mathrm{P}$ de forma mais eficiente do que Salvinia auriculata e, portanto tende a apresentar menor taxa de bioadsorção. Este processo torna-se benéfico para o ambiente, pois estes elementos, quando em altas concentrações nos corpos hídricos, conduzem à eutrofização (VON SPERLING, 2005; QUEVEDO; PAGANINI, 2011).

$\mathrm{O}$ teor de $\mathrm{P}$ na Eichhornia crassipes e na Eichhornia azurea, constatado por Silva e Esteves (1993), foram diferenciados diante da qualidade dos corpos d'água. Esta variação pode ser relacionada às condições tróficas de cada ambiente, além da relação N/P do mesmo. Henry-Silva e Camargo (2006) relatam que variações intraespecíficas nos teores de nutrientes estão associadas às diferentes condições tróficas dos ambientes aquáticos, que influenciam as taxas de crescimento e os conteúdos de nutrientes dos tecidos vegetais.

$O$ estudo de plantas aquáticas em ambientes naturais demonstra informações para 
a melhor compreensão do seu estado nutricional. Costa e Henry (2010) constataram que a espécie Salvinia auriculata apresentou os maiores teores de $\mathrm{N}$ e $\mathrm{P}$ em seus tecidos, sendo de $612{\mathrm{mg} . \mathrm{gDW}^{-1}}^{-}$

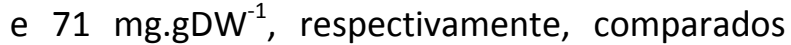

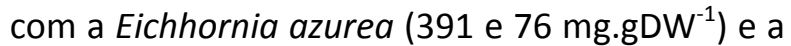
Cyperus esculentus, (567 e $67 \quad \mathrm{mg} \mathrm{gDW}^{-1}$ ) corroborando, portanto, com os resultados obtidos neste estudo.

\section{CONCLUSÕES}

Houve remoção de $\mathrm{NH}_{4}^{+}$e de $\mathrm{P}$ pelas plantas aquáticas em relação ao tratamento testemunha.

As taxas de remoção do $\mathrm{NH}_{4}{ }^{+}$do efluente foram diferenciadas entre as espécies e entre os ciclos de avaliação mensal.

A Eichhornia crassipes apresentou maior eficiência na remoção do $P$ do efluente no decorrer de todos os ciclos de avaliação mensal.

A Salvinia auriculata apresentou maior teor de $\mathrm{NH}_{4}^{+}$e $\mathrm{P}$ no tecido vegetal (raízes, bulbos e folhas).

As macrófitas aquáticas estudadas podem ser aliadas no polimento de esgoto sanitário pré-tratado em ETE, contribuindo na remoção de nutrientes ( $\mathrm{N}$ e $\mathrm{P}$ ).

\section{REFERÊNCIAS}

ALMEIDA, R. A.; OLIVEIRA, L. F. C.; KLIEMANN, H. J. Eficiência de espécies vegetais na purificação de esgoto sanitário. Pesquisa Agropecuária Tropical, v. 37, n. 1, p. 1-9, 2007.

ARIAS, C. A.; DEL BUBBA, M.; BRIX, H. Phosphorus removal by sands for use as media in subsurface flow constructed reed beds. Water Research, v. 35, n. 5, p. 1159-1168, 2001. https://doi.org/10.1016/S0043-1354(00)00368-7

BARBIERI, R.; ESTEVES, F. A. The chemical composition of some aquatic macrophyte species and implications for the metabolism of a tropical lacustrine ecosystem Lobo Reservoir. Hydrobiologia, v. 213, p. 133-140, 1991. https://doi.org/10.1007/BF00014999

COSTA, M. L. R.; HENRY, R. Phosphorus, nitrogen, and carbon contents of macrophytes in lakes lateral to a tropical river. Acta Limnologica Brasiliensia, v. 22, n. 2, p. 122-132, 2010. https://doi.org/10.1590/S2179$\underline{\text { 975X2010000200002 }}$
DINIZ, C. R.; CEBALLOS, B. S. O.; BARBOSA, J. E. L.; KONIG, A. Uso de macrófitas aquáticas como solução ecológica para melhoria da qualidade de água. Revista Brasileira de Engenharia Agrícola e Ambiental, v. 9, (supl.), p. 226-230, 2005.

ESTEVES, F. A. Fundamentos de Limnologia. 2. ed Rio de Janeiro: Interciência FINEP, 1998. 602 p.

EUSTÁQUIO, J. R. V.; MATOS, A. T.; CAMPOS, L. C.; BORGES, A. C. Desempenho agronômico da aveia-preta (Avena strigosa Schreb), cultivada em sistemas alagados construídos. Revista AmbiÁgua, v. 5, n. 1, p. 68-78, 2010.

FERRES, G. C.; MATOS, A. T.; BORGES, A. C.; CLARINDO, A. C.; SILA, R. A. Remoção de nitrogênio total, nitrato e amônio em sistemas alagados construídos de escoamento horizontal subsuperficial cultivados com Cynodon spp. e Alternanthera philoxeroides. In: SIMPÓSIO BRASILEIRO SOBRE APLICAÇÃO DE WETLANDS CONSTRUÍDOS NO TRATAMENTO DE ÁGUAS RESIDUÁRIAS, 1. Anais... Florianópolis, GESAD, 2013. p. $101-107$

GERLOFF, G. C.; KROMBHOLZ, P. H. Tissue analyses as a measure of nutrient availability for the growth of angiosperm aquatic plants. Limnology and Oceanography, v. 11, n. 4, p. 529537, 1966. https://doi.org/10.4319/lo.1966.11.4.0529

GOPAL, B. Biology and ecology. In: PATTEN, B. C. (Ed.). Wetlands and shallow continental water bodies. The Hague: SBP Academic Publishers, 1990. v. 1, 471 p.

HENRY-SILVA, G. G.; CAMARGO, A. F. M. Composição química de macrófitas aquáticas flutuantes utilizadas no tratamento de efluentes de aqüicultura. Planta Daninha, v. 24, n. 1, p. 2128 2006. https://doi.org/10.1590/S01008358200600010

HENRY-SILVA, G. G.; CAMARGO, A. F. M. Tratamento de efluentes de carcinicultura por macrófitas aquáticas flutuantes. Revista Brasileira de Zootecnia, v. 37, n. 2, p. 181-188, 2008. https://doi.org/10.1590/S1516359820080002000020003

MALAVOlTA, E.; VITTI, G. C.; OLIVEIRA, S. A. Avaliação do estado nutricional de plantas: Princípios e aplicações. 2.ed. Piracicaba: Potafós, 1997. $304 \mathrm{p}$. 
MENDONÇA, E. A. Disposição de efluentes de estação de tratamento de esgoto industrial em solo vegetado com bambu. 2010. $128 \mathrm{f}$. Dissertação (Mestrado em Engenharia do Meio Ambiente) - Universidade Federal de Goiás, Goiânia-GO, 2010. https://doi.org/10.4136/ambi$\underline{\text { agua. } 805}$

MENDONÇA, H. V. DE; RIBEIRO, C. B. M; BORGES, A. C.; BASTOS, R. R. Remoção de nitrogênio e fósforo de águas residuárias de laticínios por sistemas alagados construídos operando em bateladas. Revista Ambiente e Água, v. 7, n. 2, p. 75-87, 2012.

PETRUCIO, M. M.; ESTEVES, F. A. Uptake rates of nitrogen and phosphorus in the water by Eichhornia azurea and Salvinia auriculata. Revista Brasileira de Biologia, v. 60, n. 3, p. 229-236, $2000 . \quad$ https://doi.org/10.1590/S003471082000000200006

QUEVEDO, C. M. G.; PAGANINI, W. S. Impactos das atividades humanas sobre a dinâmica do fósforo no meio ambiente e seus reflexos na saúde pública. Ciência e Saúde Coletiva, v. 16, n. $8, \quad$ p. 3529-3539, 2011. https://doi.org/10.1590/S1413$\underline{81232011000900021}$

SEZERINO, P. H. Potencialidade dos filtros plantados com macrófitas (constructed wetlands) no pós-tratamento de lagoas de estabilização sob condições de clima subtropical. 2006. $171 \mathrm{f}$. Tese (Doutorado em Engenharia Ambiental) Universidade Federal de Santa Catarina, Florianópolis-SC, 2006.

SEZERINO, P. H.; PHILIPPI, L. S. Utilização de um sistema experimental por meio de "wetland" construído no tratamento de esgotos domésticos pós tanque séptico. In: SIMPÓSIO LUSOBRASILEIRO DE ENGENHARIA SANITÁRIA E AMBIENTAL, 9. Anais... Porto Seguro : ABES, 2000. p. 688-697.

SHAH, M.; HASHMI, H. N.; GHUMMAN, A. R.; ZEESHAN, M. Performance assessment of aquatic macrophytes for treatment of municipal wastewater. Journal of the South African Institution of Civil Engineering, v. 57, n. 3, p. 1825, 2015. https://doi.org/10.17159/23098775/2015/V57N3A3
SHUTES, R. B. E. Artificial wetlands and water quality improvement. Environment International, v. 26, n. $5 / 6, \quad$ p. 441-447, 2001. https://doi.org/10.1016/S0160-4120(01)00025-3

SILVA, C. J.; ESTEVES, F. A. Biomass of three macrophytes in the Pantanal of the Mato Grosso, Brazil. International Journal of Ecology and Management Sciences, v. 19, p. 11-23, 1993.

SOARES, A. F. S.; ARAÚJO, A. S.; RODRIGUES, N. U. A.; CUNHA, N. C. Compensação ambiental devido à falta de tratamento de esgotos domésticos no município de Campanha (MG). Ambiência, v. 12, n. 3, p. 831-839, 2016.

SOUSA, J. T.; VAN HAANDEL, A.; LIMA, E. P. C.; HENRIQUE, I. N. Utilização de wetlands construído no pós-tratamento de esgotos domésticos pré-tratados em reatores UASB. Engenharia Sanitária e Ambiental, v. 9, n. 4, p. 285-290, 2004. https://doi.org/10.1590/S1413$\underline{41522004000400004}$

UCKER, F. E.; ALMEIDA, R. A.; KEMERICH, P. D. C. Remoção de nitrogênio e fósforo do esgoto sanitário em um sistema de alagados construídos utilizando o capim vetiver. Revista Ambiente e Água, v. 7, n. 3, p. 87-98, 2012. https://doi.org/10.4136/ambi-agua. 925

VAN DE GRAAF, A. A.; DE BRUIJN, P.; ROBERTSON, L. A.; JETTEN, M. S. M.; KUENEN, J. G. Autotrophic growth of anaerobic ammoniumoxidizing micro-organisms in a fluidized bed reactor. Microbiology, v. 142, n. 8, p. 2187-2196, 1996. https://doi.org/10.1099/13500872-142-8$\underline{2187}$

VIRENDRA, K. M.; TRIPATHI, B. D. Concurrent removal and accumulation of heavy metals by the three aquatic macrophytes. Bioresorce Technology, v. 99, n. 15, p. 7091-7097, 2008. https://doi.org/10.1016/i.biortech.2008.01.002

VON SPERLING, M. Princípios do tratamento biológico de águas residuárias: introdução a qualidade das águas e ao tratamento de esgotos. 3. ed. Belo Horizonte: UFMG, 2005. 452 p.

Recebido para publicação em 21/04/2017

Revisado em30/11/2017

Aceito em 30/11/2017 